\title{
Genetic variation in sugar composition among muscadine, Florida hybrid bunch and bunch grape genotypes
}

This article was published in the following Dove Press journal:

International Journal of Wine Research

14 August 2012

Number of times this article has been viewed

\author{
Sheikh M Basha' \\ Hemanth KN Vasanthaiah' \\ Devaiah M Kambiranda' \\ Kokila Easwaran ${ }^{2}$ \\ Gilbert Queeley \\ 'Center For Viticulture and Small \\ Fruit Research, Florida A\&M \\ University, Tallahassee, FL, USA; \\ ${ }^{2}$ Centre for Plant Molecular Biology, \\ Tamil Nadu Agricultural University, \\ Coimbatore, India; ${ }^{3}$ Cooperative \\ Extension, College of Engineering \\ Technology and Agricultural Sciences, \\ Florida A\&M University, Tallahassee, \\ FL, USA
}

\begin{abstract}
Sugar content and composition of the bunch grape (Vitis vinifera) berry and its hybrids has been investigated extensively while limited information exists on the sugar content and composition of muscadine (Vitis rotundifolia) grapes. In this study, selected commercial grape cultivars belonging to muscadine, bunch, and Florida hybrid bunch market types were studied for content and composition of sugars in ripe berries for 2 consecutive years. Berry sugars were analyzed by high-performance liquid chromatography (HPLC), and the amount of sucrose, glucose, and fructose was quantified based on their peak area. Glucose and fructose were the predominant sugars in berries of bunch and Florida hybrid bunch grape genotypes and were present in almost equal amounts. In contrast, the muscadine berry contained sucrose, glucose, and fructose. Sucrose was not detected in bunch and Florida hybrid bunch grape genotypes. Glucose constituted $46.0 \%-53.0 \%$ of the total berry sugars while fructose ranged between $47.0 \%$ and $53.0 \%$ among the bunch cultivars studied. In Florida hybrid bunch cultivars, the glucose percentage varied from $39.0 \%$ to $56.0 \%$ while fructose varied from $44.0 \%$ to $53.0 \%$. In muscadine genotypes, sucrose constituted $17.0 \%-47.0 \%$, glucose $27.0 \%-39.0 \%$, and fructose $26.0 \%-47.0 \%$. The proportion of glucose and fructose was almost equal in all three categories while the level of sucrose varied widely among the muscadine genotypes indicating that variable sucrose accumulation and/or hydrolysis may influence the berry sucrose content among the grape genotypes.
\end{abstract}

Keywords: grapes, HPLC, sugars, sucrose, glucose, fructose, statistical analysis

\section{Introduction}

In grapes, a large portion of the soluble solids is represented by sugars. Among these, fructose and glucose are the primary sugars and sucrose is only found in trace amounts in certain genotypes. ${ }^{1-4}$ The organoleptic properties of the berry, flavor and stability of grape products, and wine quality greatly depends on the content and composition of sugars in berries. Further, total sugar content not only affects the quality of the grape berry but also determines the alcohol content of the wine. Moreover, glucose is also present in the bound form of flavonoid glycosides in white grapes and wines, and anthocyanins in red grapes and wines, and these glycosides can affect their antioxidant properties. More than 20 major anthocyanins (glycosides of anthocyanidins) contained in red wines were noted recently, in which the main components were 3-O-glucosides of malvidin, peonidin, petunidin, delphidin, and cyanidin. They were also found in Vitis vinifera cell suspension cultures. In addition, quercetin glucosides were found in Muscatel wines. Red wines contain carboxypyranomalvidine glucosides vitisins: vitisin A-5 carboxypyrano malvidin-3-O- $\beta$-D-glucoside47 and
Correspondence: Devaiah M Kambiranda Center for Viticulture and Small Fruit Research, Florida A\&M University,

Tallahassee, FL 32308, USA

Tel +18504125191

Fax $+|85056| 2617$

Email devaiah.kambiranda@gmail.com 
vitisin B - pyranomalvidin-3-O- $\beta$-D-glucoside. ${ }^{5}$ The sugar content and composition of the bunch grape (Vitis vinifera) berry and its hybrids has been investigated extensively ${ }^{6-8}$ while limited information exists on the sugar content and composition of muscadine (Vitis rotundifolia) grapes.

The most important commercial grapes in the world are generally classified into three groups: $V$. vinifera (bunch), Vitis rotundifolia (muscadine), and the hybrid bunch (cross between $V$. vinifera and other Vitis species). In the southeastern US, where most $V$. vinifera cultivars cannot be grown, because of the incidence of Pierce's disease (PD) and prevalence of a warm and humid climate, muscadine grapes and hybrids are the primary choice. Muscadine berries are pleasant in taste and aroma and are a delicacy for those familiar with this grape. Muscadine grapes can be eaten fresh or processed into wine, jelly, and juice. In Florida, the development of cultivars adapted to its warm and humid growing conditions has generated interest in commercial grape production. Currently most of the crop is being processed through retail markets or wine production and "U pick" operations.

Although muscadine grape products have gained wider acceptance than before, their quality and consumer acceptance is limited due to certain undesirable characteristics of the muscadine berry. For example, thick leathery skin and large seeds limit their acceptance as table grapes. Likewise, low sugar level and color stability adversely affects wine quality and shelf life. As sugar is often used to determine the time of the grape berry harvest, and to assess the potential alcohol content in the resulting wine, it is a major commercial consideration for the grape grower and winemaker. The differences in berry and wine quality between bunch grape and muscadine grape are due to variation in the amount and composition of sugars and organic acids resulting from differing genetic backgrounds between the two species. It would be valuable to study the content and composition of sugars of $V$. rotundifolia grapes and the Florida hybrid bunch (FHB) grape genotypes to assess genetic differences and to identify constraints in sugar accumulation in the muscadine grape. Moreover, muscadine and FHB grapes including table and wine grapes are being grown in greater numbers in the southeastern US to meet increasing demand. In Florida, excessive cane vigor of grapes results from sandy/sandy loam soil, and is encouraged by the significant rainfall and sunlight in the summer. These specific summer climatic conditions and vigorous vegetative growth of grape plants results in major changes in sugars and acid content of berries, compared with that of grapes grown in more temperate climates. To evaluate grape germplasm, only the measuring of soluble solids ( ${ }^{\circ}$ Brix) in grape juice has been adopted for the quantification of sugars. ${ }^{9}$ Sugars generally contribute a very large proportion to the ${ }^{\circ}$ Brix value in the ripening stage. ${ }^{1}$ However, the ${ }^{\circ}$ Brix value does not always run parallel with the sugar content since the ${ }^{\circ}$ Brix value represents the total value of soluble solids such as sugars, organic acids, and others. Furthermore, it is not possible to determine the content of individual sugars based on ${ }^{\circ}$ Brix value.

The objective of the present study was to examine variations in the content and composition of sugars in berries of the Florida-grown muscadine and FHB grape germplasm to advance our breeding program aimed at improving berry quality of muscadine and FHB grapes. Sugar analysis was carried out to determine the sugar content for different grape genotypes, to determine the relationship between genetic background ( $V$. rotundifolia, $V$. vinifera, and FHB) or intended use (table and wine grapes) and the major sugar constituents.

\section{Materials and methods Plant material}

Seventy grape cultivars belonging to muscadine ( $V$. rotundifolia), bunch (V. vinifera), and FHB (Vitis spp.) were used (Tables 1 and 2) in this study. These included both the table and wine grape cultivars. Bunch ( $V$. vinifera) grape cultivars obtained from Sonoma Nursery, CA in 2002 were maintained in a screen cage to protect them from PD. Berry samples were collected during the 2009 and 2010 seasons from the grapevines grown at the experimental vineyard of the Center for Viticulture and Small Fruit Research, Florida A\&M University, Tallahassee, FL. Standard management practices such as irrigation, fertilization, soil management, pruning, and disease control were followed in the vineyard. Sample selection and preparation of grape bunches were performed according to Marcy et a $1^{10}$ with some modifications. At ripening time, three representative average-sized bunches were collected randomly from each variety from three different grapevines. Ripeness was judged by visual observation of seed color change to dark brown without senescence of berry tissue. ${ }^{8,11,12}$ Ripeness of seedless cultivars was judged by whether or not signs of senescence were visible in berry tissues. The cultivars used in this study flowered between early May (FHB and bunch) and early June (muscadine), and ripened between late July and early September, respectively. The berry samples were taken to the laboratory immediately and frozen in liquid nitrogen and stored at $-80^{\circ} \mathrm{C}$ for later analysis of sugars. 
Table I Variation in sugar content and composition among muscadine genotypes during the years 2009 and 2010

\begin{tabular}{|c|c|c|c|c|c|c|c|c|}
\hline Cultivar & $\mathrm{pH}$ & Brix & Sucrose (S)* & Glucose (G)* & Fructose $(\mathrm{F})^{*}$ & $\mathbf{S} / \mathbf{G}$ & $\mathbf{S} / \mathbf{F}$ & $\mathbf{G} / \mathbf{F}$ \\
\hline \multicolumn{9}{|l|}{ Table grapes } \\
\hline African queen & 3.4 & 19.0 & 42 & 29 & 29 & 1.41 & 1.42 & 1.01 \\
\hline Black beauty & 3.3 & 19.0 & 31 & 34 & 35 & 0.92 & 0.89 & 0.97 \\
\hline Tara & 3.5 & 18.5 & 41 & 29 & 30 & 1.37 & 1.33 & 0.96 \\
\hline Summit** & 3.2 & 18.0 & 30 & 34 & 36 & 0.88 & 0.83 & 0.94 \\
\hline Scarlet** & 3.8 & 18.0 & 20 & 39 & 41 & 0.51 & 0.48 & 0.95 \\
\hline Doreen & 3.4 & 18.0 & 24 & 37 & 39 & 0.64 & 0.61 & 0.94 \\
\hline Jumbo & 3.5 & 18.0 & 42 & 29 & 29 & 1.45 & 1.45 & 1.00 \\
\hline Cowart & 3.5 & 18.0 & 37 & 31 & 32 & 1.16 & 1.12 & 0.97 \\
\hline Alachua & 3.7 & 17.0 & 31 & 35 & 34 & 0.89 & 0.91 & 1.03 \\
\hline Scuppernong & 3.3 & 17.0 & 25 & 34 & 41 & 0.70 & 0.58 & 0.83 \\
\hline Sugargate & 3.6 & 17.0 & 29 & 33 & 38 & 0.87 & 0.76 & 0.87 \\
\hline Loomis & 3.2 & 17.0 & 30 & 34 & 36 & 0.85 & 0.80 & 0.94 \\
\hline Darlene & 3.4 & 17.0 & 38 & 31 & 31 & 1.22 & 1.22 & 1.00 \\
\hline Ison & 3.0 & 17.0 & 31 & 34 & 35 & 0.911 & 0.88 & 0.97 \\
\hline Southland & 3.6 & 17.0 & 47 & 27 & 26 & 1.74 & 1.81 & 1.04 \\
\hline Golden isle & 3.1 & 16.5 & 29 & 34 & 37 & 0.85 & 0.78 & 0.92 \\
\hline Delight & 3.3 & 16.0 & 34 & 32 & 34 & 1.03 & 0.97 & 0.94 \\
\hline Regale & 2.9 & 16.0 & 23 & 37 & 40 & 0.62 & 0.57 & 0.92 \\
\hline Black fry & 3.3 & 16.0 & 23 & 36 & 41 & 0.64 & 0.54 & 0.86 \\
\hline Pride & 3.1 & 16.0 & 35 & 32 & 33 & 1.12 & 1.09 & 0.97 \\
\hline Dixieland & 3.6 & 16.0 & 34 & 30 & 36 & 1.13 & 0.94 & 0.83 \\
\hline Nesbit & 3.7 & 16.0 & 42 & 29 & 29 & 1.50 & 1.45 & 0.96 \\
\hline Albermale & 3.4 & 16.0 & 29 & 37 & 34 & 0.78 & 0.85 & 1.09 \\
\hline Hunt & 3.3 & 16.0 & 39 & 32 & 29 & 1.22 & 1.34 & 1.10 \\
\hline Higgins & 3.3 & 16.0 & 35 & 32 & 33 & 1.09 & 1.06 & 0.97 \\
\hline Rosa & 3.3 & 16.0 & 35 & 32 & 33 & 1.09 & 1.06 & 0.97 \\
\hline Sugar pop & 3.1 & 16.0 & 26 & 37 & 37 & 0.70 & 0.70 & 1.00 \\
\hline Supreme** & 3.6 & 15.1 & 28 & 33 & 39 & 0.85 & 0.72 & 0.85 \\
\hline Pineapple & 3.4 & 15.0 & 44 & 28 & 28 & 1.53 & 1.53 & 1.00 \\
\hline Triumph & 3.6 & 15.0 & 22 & 37 & 41 & 0.56 & 0.51 & 0.90 \\
\hline Farrer & 3.5 & 15.0 & 32 & 35 & 33 & 0.91 & 0.97 & 1.06 \\
\hline Fry seedless & 3.0 & 15.0 & 17 & 39 & 44 & 0.41 & 0.36 & 0.89 \\
\hline Janet & 3.4 & 15.0 & 40 & 30 & 30 & 1.33 & 1.33 & 1.00 \\
\hline Fry** & 3.8 & 15.0 & 30 & 32 & 38 & 0.97 & 0.81 & 0.84 \\
\hline Sweet jenny & 3.3 & 15.0 & 33 & 33 & 34 & 1.00 & 0.97 & 0.97 \\
\hline Digby & 3.3 & 14.0 & 23 & 30 & 47 & 0.76 & 0.49 & 0.64 \\
\hline Dixie red & 3.3 & 14.0 & 26 & 33 & 41 & 0.79 & 0.62 & 0.78 \\
\hline Senoia & 3.4 & 14.0 & 38 & 30 & 32 & 1.27 & 1.19 & 0.94 \\
\hline Watergate & 3.4 & 13.5 & 34 & 30 & 36 & 1.13 & 0.94 & 0.83 \\
\hline Jane bell & 3.2 & 13.0 & 25 & 34 & 41 & 0.73 & 0.61 & 0.83 \\
\hline Sterling & 3.2 & 12.5 & 25 & 30 & 45 & 0.83 & 0.55 & 0.67 \\
\hline Majesty & 3.4 & 12.0 & 32 & 33 & 35 & 0.97 & 0.94 & 0.94 \\
\hline Pam & 3.5 & 11.0 & 32 & 33 & 35 & 0.97 & 0.91 & 0.97 \\
\hline Granny val & 3.4 & 10.0 & 30 & 34 & 36 & 0.88 & 0.83 & 0.94 \\
\hline \multicolumn{9}{|l|}{ Wine grapes } \\
\hline Welder $* *$ & 3.4 & 18.5 & 37 & 29 & 34 & 1.24 & 1.05 & 0.94 \\
\hline Magnolia** & 3.2 & 17.0 & 35 & 32 & 33 & 1.06 & 1.03 & 0.97 \\
\hline Noble** & 2.8 & 17.0 & 32 & 33 & 35 & 0.97 & 0.91 & 0.94 \\
\hline Carlos** & 2.9 & 15.0 & 19 & 37 & 44 & 0.51 & 0.42 & 0.82 \\
\hline
\end{tabular}

Notes: *Individual sugar content is expressed as percent of total sugar (sucrose + glucose + fructose) peak area; ** genotypes used for statistical analysis.

\section{Estimation of $\mathrm{pH}$ and ${ }^{\circ}$ Brix}

$\mathrm{pH}$ and ${ }^{\circ} \mathrm{Brix}$ of the berries were analyzed using a $\mathrm{pH}$ meter and refractometer (Atago, Tokyo, Japan), respectively to determine the $\mathrm{pH}$ level and total soluble solids of the berries.

\section{Sugar analysis}

Sugars were analyzed using a Waters HPLC system (Waters Corporation, Milford, MA). ${ }^{13}$ The frozen berry samples were thawed at $25^{\circ} \mathrm{C}$, sliced into $2-3 \mathrm{~mm}$ thick pieces and ground into a powder using a mortar and pestle with liquid nitrogen 
Table 2 Variation in sugar content and composition among hybrid bunch and bunch grape genotypes for the years 2009 and 2010

\begin{tabular}{|c|c|c|c|c|c|c|c|c|}
\hline Cultivar & pH & Brix & Sucrose (S)* & Glucose (G)* & Fructose (F)* & $\mathbf{S} / \mathbf{G}$ & $\mathbf{S} / \mathbf{F}$ & $\mathbf{G} / \mathbf{F}$ \\
\hline \multicolumn{9}{|c|}{ Florida hybrid bunch (Vitis spp.) } \\
\hline \multicolumn{9}{|c|}{ Wine grapes } \\
\hline Lake emerald** & 3.6 & 19.2 & 0 & 47 & 53 & 0 & & 0.89 \\
\hline Black spanish & 3.6 & 19.0 & 0 & 48 & 52 & 0 & & 0.92 \\
\hline Suwannee** & 3.4 & 16.0 & 0 & 47 & 53 & 0 & & 0.89 \\
\hline Midsouth** & 3.5 & 16.0 & 0 & 51 & 49 & 0 & & 1.04 \\
\hline Conquistador** & 3.2 & 15.0 & 14 & 39 & 47 & 0.35 & 0.30 & 0.84 \\
\hline Blue lake** & 3.5 & 13.0 & 0 & 48 & 52 & 0 & & 0.92 \\
\hline Blanc du bois** & 3.9 & 12.0 & 0 & 48 & 52 & 0 & & 0.92 \\
\hline Cynthiana** & 3.5 & 19.0 & 0 & 47 & 53 & 0 & & 0.89 \\
\hline Stover** & 3.7 & 17.0 & 0 & 48 & 52 & 0 & & 0.92 \\
\hline Tampa & 3.0 & 18.0 & 0 & 49 & 51 & 0 & & 0.96 \\
\hline Daytona & 3.2 & 16.0 & 0 & 50 & 50 & 0 & & 1.00 \\
\hline Florilush & 3.8 & 14.0 & 0 & 56 & 44 & 0 & & 1.27 \\
\hline \multicolumn{9}{|l|}{ Bunch (Vitis vinifera) } \\
\hline \multicolumn{9}{|l|}{ Table grapes } \\
\hline Red globe** & 3.7 & 21 & 1 & 48 & 51 & 0.02 & 0.02 & 0.94 \\
\hline \multicolumn{9}{|l|}{ Thompson } \\
\hline Seedless $* *$ & 3.7 & 21 & 0 & 47 & 53 & 0 & 0 & 0.89 \\
\hline Black (ribier/concord)** & 3.9 & 21 & 0 & 50 & 50 & 0 & 0 & 1.00 \\
\hline Thomcord** & 3.5 & 21 & 2 & 46 & 52 & 0.04 & 0.04 & 0.89 \\
\hline \multicolumn{9}{|l|}{ Wine grapes } \\
\hline Merlot** & 3.6 & 14 & 0 & 50 & 50 & 0 & 0 & 1.00 \\
\hline Ruby cabernet & 2.5 & 14 & 0 & 50 & 50 & 0 & 0 & 1.00 \\
\hline Zinfandel** & 3.0 & 17 & 0 & 51 & 49 & 0 & 0 & 1.04 \\
\hline Chardonnay** & 3.0 & 13 & 0 & 50 & 50 & 0 & 0 & 1.00 \\
\hline Chenin blanc & 3.2 & 12 & 0 & 53 & 47 & 0 & 0 & 1.12 \\
\hline Barbara** & 2.5 & 15 & 0 & 51 & 49 & 0 & 0 & 1.24 \\
\hline
\end{tabular}

Notes: *Individual sugar content is expressed as percent of total sugar (sucrose + glucose + fructose) peak area; **genotypes used for statistical analysis.

and centrifuged at 20,000 $\mathrm{g}$ for 15 minutes. An aliquot $(1 \mathrm{~mL})$ of the supernatant was passed through a Sep-Pak ${ }^{\circledR}$ C18 cartridge (Waters Corporation), and then diluted to $3 \mathrm{~mL}$ with double-distilled water. The diluted sample was passed through a $0.45 \mu \mathrm{m}$ nylon membrane filter (Whatman, Piscataway, NJ) and $10 \mu \mathrm{L}$ samples were injected. The HPLC system consisted of a Sugar Pak column $(300 \mathrm{~mm} \times 6.5 \mathrm{~mm}$, Water Sugar Pak I column), equipped with a guard column cartridge (Sugar Pak II inserts), 2414 Refractive Index detector, and 717 Autosampler (Waters Corporation). The column temperature was maintained at $90^{\circ} \mathrm{C}$ with a Waters TCM thermo stated column compartment. The column was eluted with double-distilled water containing $0.0001 \mathrm{M}$ calcium EDTA $(50 \mathrm{mg} / \mathrm{L})$ at a flow rate of $0.5 \mathrm{~mL} /$ minute. The Empower (Waters Corporation) chromatography data system was used to integrate peak areas according to external standard solution calibrations. Sugar content was expressed as percentage of the total sugars peak area.

\section{Statistical analysis}

Data for each cultivar in each year represents an average of three replications. Mean values of these replications were used for subsequent statistical analysis. The cultivar variation of sugar contents was analyzed using StatistiXL (StatistiXL, Perth, Western Australia, available at: http://www.statistixl. com), a powerful new data analysis package.

\section{Principal component analysis}

To obtain an overview of correlations between sugar content and composition, and the relationship between genetic background or intended use and major sugar constituents, principal component analysis (PCA) was performed using the "princomp" function of StatistiXL. This procedure was applied to standardize variables, ie to variables computed by subtracting the mean and then dividing by the standard deviation of each original variable to give each variable equal weight in the analysis. The standardized data of each year were averaged and subjected to PCA. With PCA, the data can be reduced to a set of new latent variables called principal components (PCs). The loadings of the PC define the direction of greatest variability and the score values represent the projection of each object onto PC. The first $\mathrm{PC}$ is the linear combination of the original variables which explains the greatest variability. The second PC has been 
defined to be orthogonal to the first one and explains the second greatest amount of variability. The analysis proceeds until all PCs are obtained, the number of which is typically much smaller than the variables.

\section{t-test}

The independent samples $t$-test was applied to determine significant difference in sugars, the ratio of glucose/ fructose, sucrose/glucose, and sucrose/fructose, and ratios between different genotypes using StatistiXL. This method was also used to study the stability of sugars in the genotypes between the two seasons by the paired samples $t$-test.

\section{Results \\ Estimation of $\mathrm{pH}$ and ${ }^{\circ}$ Brix}

The $\mathrm{pH}$ and ${ }^{\circ} \mathrm{Brix}$ measurement of the grape berries showed no major differences in $\mathrm{pH}$, while ${ }^{\circ}$ Brix values differed widely among the Vitis spp. (Tables 1 and 2). The soluble sugars content was highest in bunch grapes (21 $\left.{ }^{\circ} \mathrm{Brix}\right)$ followed by FHB (20 ${ }^{\circ}$ Brix $)$ and muscadine ( $18.5^{\circ}$ Brix $)$ grapes. The $\mathrm{pH}$ of bunch grapes was 2.5-3.9, FHB was 3.0-3.8, and muscadine was $2.8-3.8$. The ${ }^{\circ}$ Brix value for bunch grapes grown in Florida is relatively lower compared with the reported values possibly because of the prevailing hot and humid climatic conditions and suboptimal berry development and ripening status, since the bunch grapes were grown in PD-free cages ${ }^{15}$ and not in the open field.

\section{Genotypic variation in sugar content}

The results showed that the content and composition of sugars varied considerably among the genotypes studied. HPLC resolved grape berry sugars into three major peaks corresponding to sucrose, glucose, and fructose. The primary sugars were generally glucose and fructose in all the bunch and FHB genotypes, and sucrose, glucose, and fructose in all the muscadine genotypes (Tables 1 and 2). The glucose and fructose content in FHB ranged 39\%-56\% and 44\%-53\%, respectively. The sucrose content of the muscadine berries ranged $17 \%-47 \%$, glucose ranged $27 \%-39 \%$, and fructose ranged $26 \%-47 \%$. Of the 13 FHB genotypes studied, sucrose was detected in only one genotype, viz Conquistador at about $14 \%$, with glucose and fructose content being $39 \%$ and $47 \%$, respectively. Among the ten bunch genotypes tested, sucrose was detected only in Red Globe and Thomcord at about $1 \%$ and $2 \%$, respectively, while glucose and fructose content varied $46 \%-53 \%$ and $47 \%-53 \%$, respectively. It should be noted that Red Globe and Thomcord were purchased from a local grocery store (Publix) and were not grown in Florida while the other bunch genotypes were all grown in Tallahassee, $\mathrm{FL}$, in a screen cage to protect them from PD. Additionally, in muscadine genotypes, sucrose to glucose and sucrose to fructose ratios were higher compared with the glucose to fructose ratio. In bunch and FHB grape genotypes, the glucose to fructose ratio was higher, and sucrose to glucose/ fructose ratios were negligible.

Eight cultivars from each Vitis spp. representing table and wine varieties (Tables 1 and 2) were selected and subjected to statistical analysis. A box and whisker plot was developed using StatistiXL to estimate the frequency distribution of the relative content of sucrose, glucose, and fructose among the 24 genotypes studied (Figure 1). Approximately $99 \%$ of the data fell inside the whiskers. The data outside these whiskers are indicated by vertical lines (the lines extending from the top and bottom of the boxes). The median of fructose content in grape berries for all the cultivars was $41 \%$, and the averages were significantly higher $(P<0.001)$ than that of glucose $(46.04 \%)$. The median of glucose content in grape berries for all the cultivars was $49 \%$, and the averages were significantly lower $(P<0.001)$ than that of fructose $(43.13 \%)$. The ratio of glucose/fructose, sucrose/glucose, and sucrose/fructose in berries varied with cultivar and ranged 0.42-1.24.

The sucrose content was very high in all the muscadine cultivars (Table 1) studied, but it was less than $0.5 \mathrm{mg} \mathrm{mL}^{-1}$ in Conquistador $\left(0.35 \mathrm{mg} \mathrm{mL}^{-1} ; \mathrm{FHB}\right)$, Thomcord $\left(0.04 \mathrm{mg} \mathrm{mL}^{-1}\right.$; Vitis spp.), and Red Globe (0.02 $\mathrm{mg} \mathrm{mL}^{-1}$; Vitis vinifera) (Table 2). Sucrose was not detected in all the other bunch and FHB genotypes studied during both years. Among the muscadines, the highest sucrose content was recorded in the cultivars Welder and Magnolia, which are used in winemaking. The sucrose content of these varieties was 1.24 (Welder) and $1.06 \mathrm{mg} \mathrm{mL}^{-1}$ (Magnolia), which accounted for 36\% and $34 \%$ of the total soluble sugars of the berry. Among the Vitis species studied, the highest sugar content was observed in Zinfandel (23 ${ }^{\circ}$ Brix; Vitis vinifera) followed by Lake Emerald (20 ${ }^{\circ}$ Brix; FHB) and Welder (18.5 ${ }^{\circ}$ Brix; muscadine). These results indicate that muscadine grapes contain relatively lower levels of sugars and higher sucrose content compared with FHB and bunch grape genotypes.

\section{Principal component analysis}

The result of principal component (PC) analysis for sugars of different grape genotypes is shown in Figure 2. The first three PCs (sucrose, glucose, and fructose) accounted for 92.1\% (muscadine), 86.1\% (FHB), and 73.1\% (bunch) of 

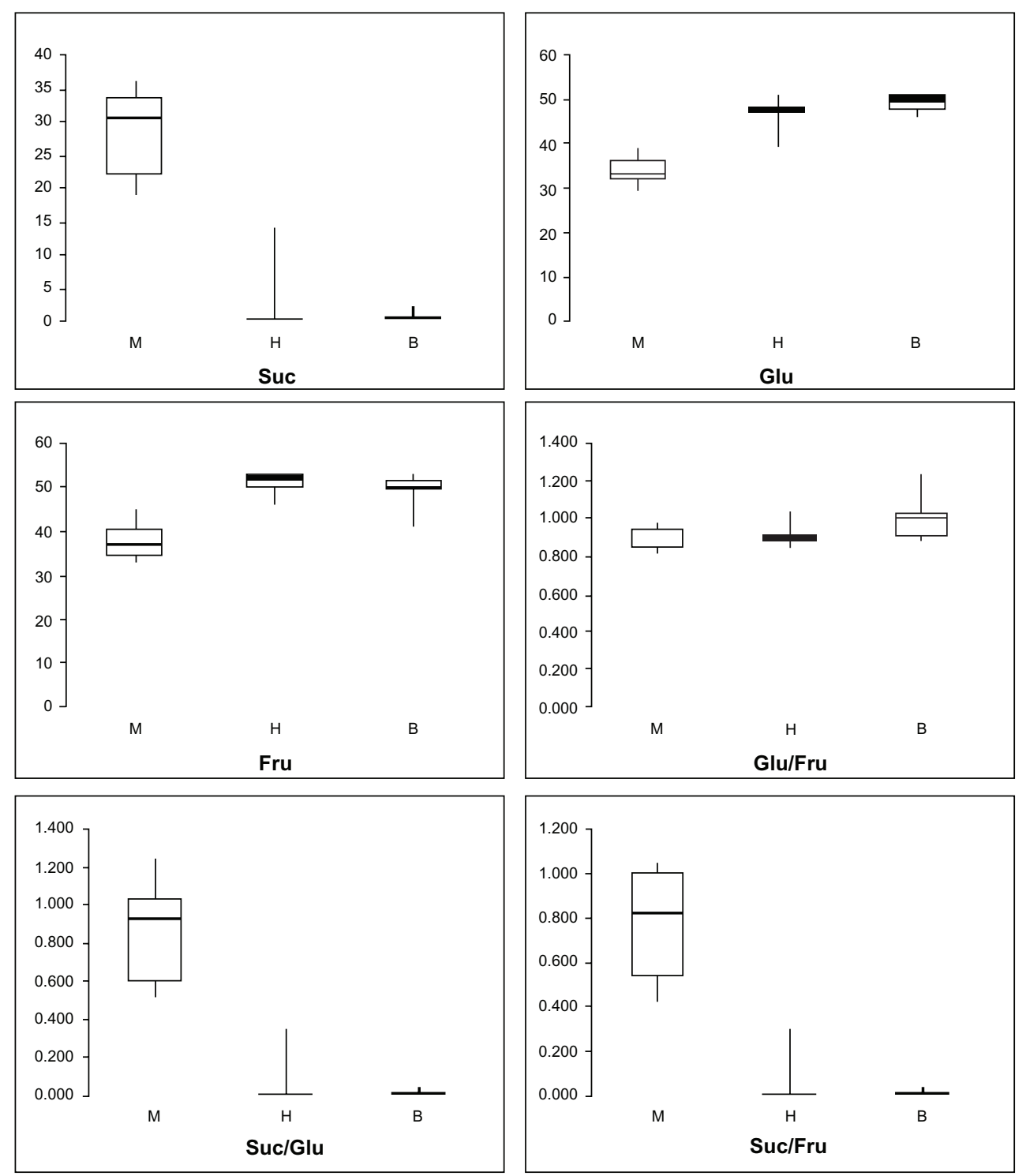

Figure I Range and distribution of grape berry sugars.

Notes: The horizontal lines in the interior of the box are the median values. The height in a box is equal to the interquartile distance, indicating the distribution for $50 \%$ of the data. Approximately $99 \%$ of the data fall inside the whiskers. The data outside these whiskers are indicated by vertical lines.

Abbreviations: Suc, sucrose; Glu, glucose; Fru, fructose; B, bunch; H, Florida hybrid bunch; M, muscadine.

total variance in both the years. PC1 was highly connected with glucose and fructose contents, exhibiting negative value. However, the components of PC2 exhibited positive value. PC1 and PC2 analysis explained a high percentage of the total variance. In muscadine and FHB cultivars, glucose and fructose were the main contributors of total variance whereas in bunch grape, fructose and sucrose were the main contributors. However, both exhibited negative and positive values for $\mathrm{PC} 1$, respectively.

\section{$t$-test}

The paired $t$-test focuses on the difference between the paired data and reports the probability that the actual mean difference is zero. This comparison is aided by the reduction in variance achieved by taking the differences. The actual mean here refers to the mean of all the eight cultivars selected from statistical analysis. In this case, four wine and four table types were selected from the three grape species. However, analysis revealed that the average difference is significantly different from zero in the case of FHB and bunch grape cultivars compared with muscadine. This would mean that there are differences in sucrose:glucose:fructose ratios among these species. The stability of different sugar contents among genotypes over the 2 years was determined using paired samples $t$-tests (Tables 3-6). Significant differences in sucrose and ratios of sucrose/glucose and sucrose/fructose were observed in FHB and bunch genotypes compared with muscadine genotypes. 

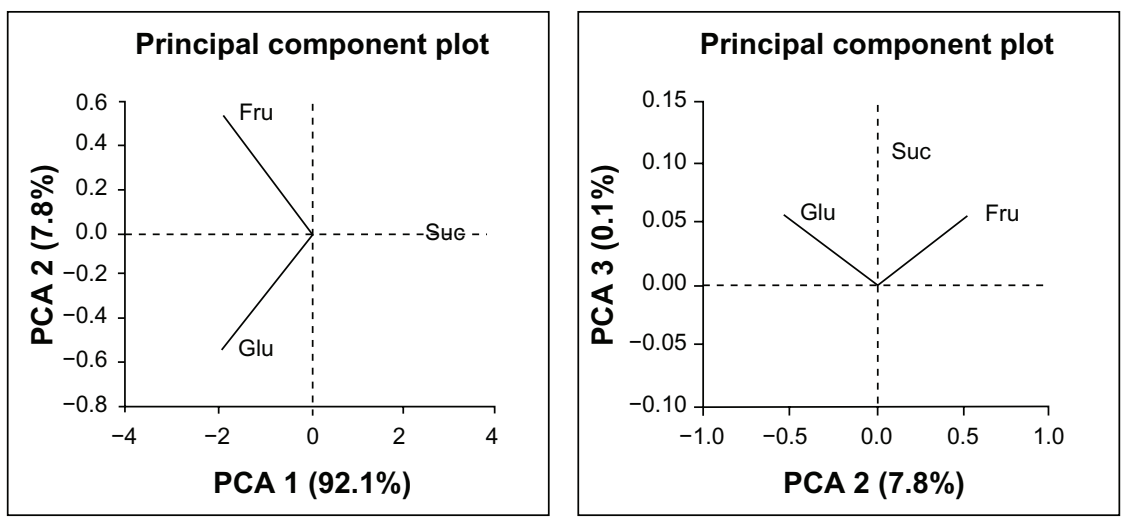

Muscadine
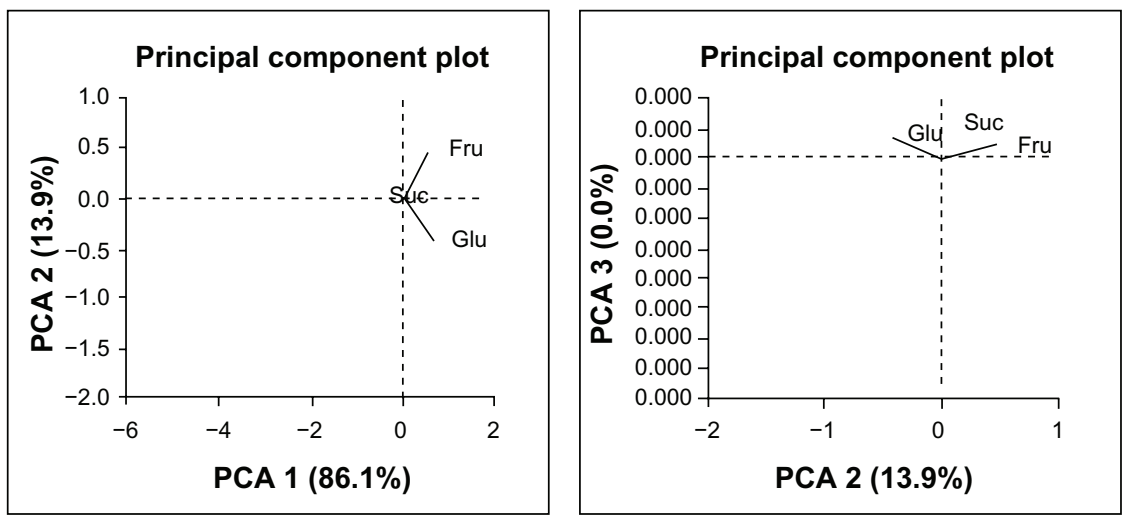

\section{Florida hybrid \\ bunch}
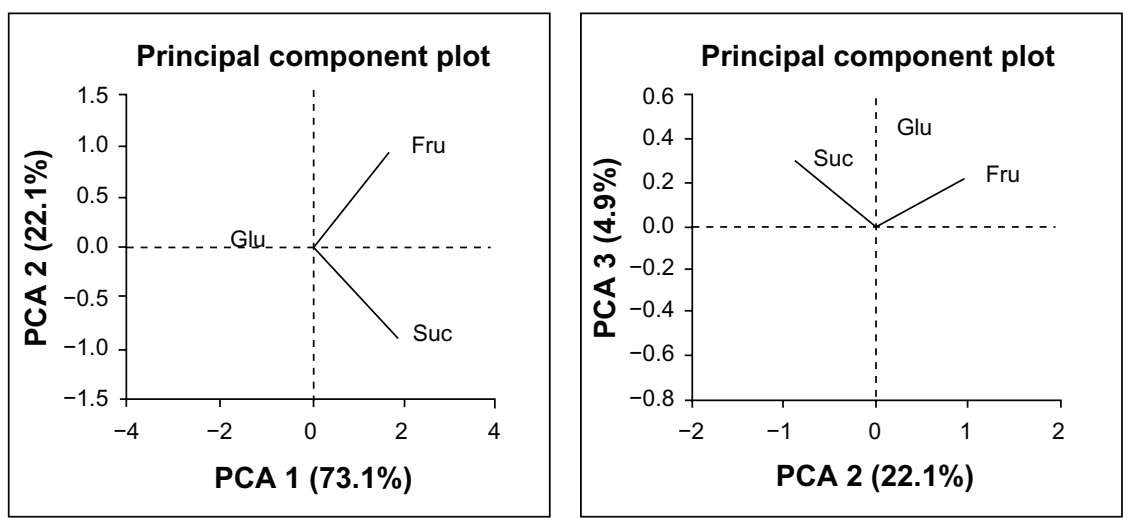

Bunch

Figure 2 Plots of sugars (sucrose + glucose + fructose) for the first two principal components. Percentages in parenthesis represent the variance of each component. Original data on sugars are expressed as $\mathrm{mg} \mathrm{mL}^{-1}$ juice.

Abbreviations: Fru, fructose; Glu, glucose; Suc, sucrose; PCA, principal component analysis.

\section{Discussion}

Grape berries, when ripe, contain high levels of sugars that are important for flavor and fermentation. Sugars also provide the osmotic driving force for cell expansion ${ }^{14}$ as well as modulating gene expression ${ }^{15}$ through signaling mechanisms. ${ }^{16}$. The movement of sugars into fruits is a tightly regulated process, which is coordinated with growth and development. The accumulation of sugars in grape berries begins at the onset of ripening, known as veraison, and is marked by a ten-fold increase in hexose content. ${ }^{3}$ Sucrose is one of the main translocatable sugars as a result of photosynthesis. Glucose and fructose are the primary sugars of grape (Vitis spp.), and sucrose presents in trace amounts. ${ }^{1-3}$ However, some American hybrid cultivars such as "Bath", "Buffalo", "Fredonia", and "Steuben", and Vitis $\times$ labruscana contain large amounts of sucrose. ${ }^{17-19}$ The order of sweetness is: fructose $>$ sucrose $>$ glucose. In other words, on a scale of sweetness, if fructose is considered to be 100 , then sucrose is 84 and glucose is 66 . The accumulation of sugars in grapes has been extensively studied in Vitis vinifera but limited studies exist in FHB and muscadine grapes. 
Table 3 Comparative analysis of Vitis spp. for $\mathrm{pH}$, Brix, sucrose, glucose, and fructose content $(\mathrm{df}=23)$ using paired samples $t$-test

\begin{tabular}{lllll}
\hline Variable & Mean & SE & t-value & $\begin{array}{l}\text { P-value } \\
\text { (2-tailed) }\end{array}$ \\
\hline $\mathrm{pH}$ & 3.357 & 0.086 & 38.852 & 0.000 \\
Brix & 16.950 & $0.55 \mathrm{I}$ & 30.757 & 0.000 \\
Sucrose (suc) & 10.458 & 2.847 & 3.674 & 0.001 \\
Glucose (glu) & 43.125 & 1.517 & 28.424 & 0.000 \\
Fructose (fru) & 46.042 & 1.425 & 32.309 & 0.000 \\
Suc/glu & 0.312 & 0.089 & 3.507 & 0.002 \\
Suc/fru & 0.279 & 0.080 & 3.503 & 0.002 \\
Glu/fru & 0.940 & 0.018 & 52.346 & 0.000 \\
\hline
\end{tabular}

Abbreviation: SE, standard error.

Based on screening of 70 grape genotypes belonging to muscadine, Florida hybrids, and bunch grapes, a total of 50 genotypes were found to accumulate sucrose at varying degrees with the highest in muscadine and one each among Florida hybrid and bunch grapes. A soluble sugars profile has enabled us to distinguish muscadine cultivars from the bunch and FHB grape genotypes based on the predominance of sucrose in their sugar profile. Sucrose buildup was a unique characteristic of all the muscadine genotypes tested with percentages ranging $17 \%-47 \%$ in all the muscadine genotypes studied, with the highest being in Southland (47\%) and lowest in Fry seedless (17\%). Sucrose content was different among the cultivars that are likely to be useful genetic resources to broaden variability for sugar composition in grapes. However, the physiological and genetic basis for sugar accumulation has not been investigated by researchers.

The result of PCA confirms the previous conclusion on sugar content. PC1 was highly connected with glucose and fructose content which exhibited negative value in muscadine cultivars and positive value among FHB and bunch grape cultivars. Whereas PC2 exhibited positive value for sucrose and

Table 4 Paired samples $t$-test for comparing $\mathrm{pH}$, Brix, sucrose, glucose, and fructose contents $(\mathrm{df}=7)$ among muscadine grape genotypes

\begin{tabular}{lllll}
\hline Variable & Mean & SE & t-value & $\begin{array}{l}\text { P-value } \\
\text { (2-tailed) }\end{array}$ \\
\hline pH & 3.338 & 0.135 & 24.745 & 0.000 \\
Brix & 16.700 & 0.520 & 32.118 & 0.000 \\
Sucrose (suc) & 28.750 & 2.194 & 13.105 & 0.000 \\
Glucose (glu) & 33.625 & 1.101 & 30.542 & 0.000 \\
Fructose (fru) & 37.625 & 1.413 & 26.620 & 0.000 \\
Suc/glu & 0.874 & 0.090 & 9.719 & 0.000 \\
Suc/fru & 0.781 & 0.082 & 9.498 & 0.000 \\
Glu/fru & 0.906 & 0.021 & 43.427 & 0.000 \\
\hline
\end{tabular}

Abbreviation: SE, standard error.
Table 5 Paired samples $t$-test for comparing $\mathrm{pH}$, Brix, sucrose, glucose, and fructose contents $(\mathrm{df}=7)$ among Florida hybrid bunch grape genotypes

\begin{tabular}{lllll}
\hline Variable & Mean & SE & t-value & $\begin{array}{l}\text { P-value } \\
\text { (2-tailed) }\end{array}$ \\
\hline $\mathrm{pH}$ & 3.538 & 0.073 & 48.432 & 0.000 \\
Brix & 15.900 & 0.908 & 17.513 & 0.000 \\
Sucrose (suc) & 1.750 & 1.750 & 1.000 & 0.351 \\
Glucose (glu) & 46.875 & 1.217 & 38.532 & 0.000 \\
Fructose (fru) & 51.250 & 0.881 & 58.149 & 0.000 \\
Suc/glu & 0.044 & 0.044 & 1.000 & 0.351 \\
Suc/fru & 0.038 & 0.038 & 1.000 & 0.351 \\
Glu/fru & 0.914 & 0.020 & 44.905 & 0.000 \\
\hline
\end{tabular}

Abbreviation: SE, standard error.

fructose contents among muscadine and FHB cultivars, and positive value of glucose and fructose content in bunch grape cultivars, respectively. Thus the concentrations of glucose and fructose in cultivars tend to increase proceeding from positive to negative values of $\mathrm{PC} 1$ and $\mathrm{PC} 2$, meaning a general increase in sugar content and a decrease in sucrose content.

Further studies on the stability of sugars among the genotypes based on paired sample $t$-tests showed that the sugar content was stable over the 2-year study period (Table 3 ). The results showed that there was no significant difference in sucrose, glucose, fructose, and total sugar content or in the ratios of glucose/fructose and sucrose/glucose, and sucrose/fructose among bunch cultivars (Tables 5 and 6). However, significant differences in sucrose and ratios of glucose/fructose, sucrose/glucose, and sucrose/fructose were observed in muscadine and bunch cultivars. This indicates that the genetic makeup of the plant may have a greater influence on the sugar content of grape cultivars. Another reason may be that differences in the expression levels of sugar metabolizing genes among the genotypes may influence the sugar content in the grape berries. ${ }^{20}$ Our previous studies showed lower

Table 6 Paired samples t-test for comparing $\mathrm{pH}$, Brix, sucrose, glucose, and fructose contents $(\mathrm{df}=7)$ among bunch grape genotypes

\begin{tabular}{lllll}
\hline Variable & Mean & SE & t-value & $\begin{array}{l}\text { P-value } \\
\text { (2-tailed) }\end{array}$ \\
\hline $\mathrm{pH}$ & 3.363 & 0.169 & $19.90 \mathrm{I}$ & 0.000 \\
Brix & 20.750 & 0.412 & 50.379 & 0.000 \\
Sucrose (suc) & 0.375 & 0.263 & 1.426 & 0.197 \\
Glucose (glu) & 49.125 & 0.666 & 73.708 & 0.000 \\
Fructose (fru) & 49.500 & 1.296 & 38.206 & 0.000 \\
Suc/glu & 0.008 & 0.005 & 1.426 & 0.197 \\
Suc/fru & 0.008 & 0.005 & 1.426 & 0.197 \\
Glu/fru & 1.000 & 0.039 & $25.37 \mathrm{I}$ & 0.000 \\
\hline
\end{tabular}

Abbreviation: SE, standard error. 
invertase activity in muscadine genotypes compared with FHB and bunch grape cultivars, ${ }^{21}$ confirming this observation.

The hexose- and sucrose-accumulating characteristics in grape berries are thought to be related to regional and genetic differences since a sucrose accumulator has not yet been found among the $V$. vinifera cultivars. American hybrid cultivars have V. labrusca in their parentage, and the gene(s) regulating sugar metabolism may differ in that species. Inheritance of sucrose accumulation in grapevine is not clear but preliminary genetic studies indicated that it is a recessive trait. ${ }^{4,10}$ Biochemical investigations of sugar metabolism in grape berries suggest that sucrose accumulation could result from low activity of acid invertase which hydrolyzes sucrose to glucose and fructose. ${ }^{4,16-19}$ Our previous study on acid invertase enzyme revealed that muscadine grapes contain relatively low levels of acid invertase compared with bunch and FHB grapes. ${ }^{16}$ Low invertase activity might result in sucrose buildup in muscadine genotypes. Further, our result suggests that the content and composition of sugars in berries depend largely upon genotype and the growth environment. Higher sugars, especially higher fructose in the berries of bunch and FHB than those of muscadine cultivars, makes the former sweeter. Enhancing enzyme activities required for sucrose breakdown may result in lower sucrose and higher glucose and fructose in muscadine berries which might increase their enological and flavor characteristics.

\section{Conclusion}

Sugar composition in muscadine grape berries is different from bunch and FHB grapes. This indicates that the genetic makeup of muscadine grapes may have a greater influence on the berry sugar content and composition. Sucrose was among the major sugars apart from glucose and fructose in all the muscadine berries tested suggesting that variable sucrose accumulation and/or hydrolysis may influence the berry sucrose content among the grape genotypes.

\section{Acknowledgment}

We acknowledge USDA-NIFA-CBG, Viticulture Advisory Committee, Florida Department of Agriculture, Tallahassee, FL for their financial support.

International Journal of Wine Research

\section{Publish your work in this journal}

The International Journal of Wine Research is an international, peer-reviewed open-access, online journal focusing on all scientific aspects of wine, including: vine growing; wine elaboration; human interaction with wine; and health aspects of wine. The journal provides an open access platform for the reporting

\section{Disclosure}

The authors report no conflicts of interest in this work.

\section{References}

1. Winkler AJ, Cook JA, Kliewer WM, et al. Development and Composition of Grapes. In: General Viticulture. Berkeley, Los Angeles, London: University of California Press; 1974:138-196.

2. Shiraishi M. Three descriptions for sugars to evaluate grape germplasm. Euphytica. 1993;71:99-106.

3. Davies C, Robinson SP. Sugar accumulation in grape berries. Plant Physiol. 1996;111:275-283.

4. Shiraishi M, Fujishima H, Chijiwa H. Tetraploid sucrose-accumulating Grapevines. Vitis. 2008;47:191-192.

5. Lachman J, Aulc M, Faitov K, Pivec V. Major factors influencing antioxidant contents and antioxidant activity in grapes and wines. Int J Wine Res. 2009;1:101-121.

6. Amerine MA, Whinkler AJ. Maturity studies of California grapes. III. The acid content of grapes leaves, $\mathrm{pH}$, and organic acid content. Proc Am Soc Hort Sci. 1958;71:199-206.

7. Kliewer WM. The glucose and fructose ratio of $V$. vinifera grapes. Am J Enol Viti. 1967;18:33-41.

8. Shiraishi M. Proposed descriptors for organic acids to evaluate grape germplasm. Euphytica. 1995;81:13-20.

9. International Plant genetic resources. Descriptors for grapevine (Vitis spp). International Plant Genetic Resources Institute, Rome; 1997.

10. Marcy JE, Carroll DE, Young CT. Changes in free amino acid and total nitrogen concentrations during maturation of muscadine grapes (V. rotundifolia). J Food Sci. 1981;46:543-547.

11. Shiraishi M, Fujishima H, Chijiwa H. Evaluation of table grape genetic resources for sugar, organic acid, and amino acid composition of berries. Euphytica. 2010;174:1-13.

12. Liu HF, Wu BH, Fan PG, et al. Inheritance of sugars and acids in berries of grape. Euphytica. 2007;153:99-107.

13. Basha SM. Soluble sugar composition of peanut seed. J Agri Food Chem. 1992;40:780-783.

14. Stadler R, Truernit E, Gahrtz M, et al. The AtSUC1 sucrose carrier may represent the osmotic driving force for anther dehiscence and pollen tube growth in Arabidopsis. Plant J. 1999;19:269-278.

15. Koch KE. Carbohydrate modulated gene expression in plants. Ann Rev Plant Physiol Plant Mol Biol. 1996;47:509-540.

16. Lalonde S, Boles E, Hellmann $\mathrm{H}$, et al. The dual function of sugar carriers: transport and sugar sensing. Plant Cell. 1999;11:707-726.

17. Lott RV, Barett HC. The dextrose, levulose, sucrose, and acid content of the juice from 39 grape clones. Vitis. 1996;6:257-268.

18. Motomura Y. Accumulation and metabolism of sucrose in grape berries varying with cultivar. XXIV International Horticultural Congress. 1994; Poster sessions: 247 [abstr].

19. Takayanagi T, Yokotsuka K. Relationship between sucrose accumulation and sucrose metabolizing enzymes in developing berries. Amer $J$ Enol Vitic. 1997;48:403-407.

20. Jain AK, Basha SM, Lorenzo AB, et al. Variation on the sugar accumulation pattern of Muscadine grape genotypes. Proc Flor Hort Soc. 2002;115:329-336.

21. Kambiranda D, Vasanthaiah HKN, Sheikh MB. Relationship between acid invertase activity and sugar content in grape species. $J$ Food Biochem. doi: 10.1111/j.1745-4514.2010.00483.x.

\section{Dovepress}

of evidence based studies on these topics. The manuscript management system is completely online and includes a very quick and fair peer-review system, which is all easy to use. Visit http://www.dovepress.com/testimonials.php to read real quotes from some of our published authors. 